\title{
O MÉTODO FENOMENOLÓGICO NAS PESQUISAS EM SAÚDE NO BRASIL: UMA ANÁLISE DE PRODUÇÃO CIENTÍFICA
}

\author{
THE PHENOMENOLOGICAL METHOD IN HEALTH RESEARCHES IN \\ BRAZIL: AN ANALYSIS OF SCIENTIFIC PRODUCTION \\ EL MÉTODO FENOMENOLÓGICO EN LAS INVESTIGACIONES EN SALUD \\ EN BRASIL: UN ANÁLISIS DE PRODUCCIÓN CIENTÍFICA
}

Rosilda Verissimo Silva ${ }^{1}$

Walter Ferreira de Oliveira ${ }^{2}$

Resumo A fenomenologia como modelo investigativo mostra-se como possibilidade de aproximação entre os profissionais de saúde e usuários do sistema de cuidado à saúde. Este estudo visa contribuir no processo de apropriação filosófica desse enfoque nas investigações nessa área. A pesquisa foi realizada com o objetivo de analisar a produção periódica científica relacionada à temática, identificando os fenômenos avaliados nesses estudos, as perspectivas teóricas fenomenológicas abordadas, bem como os campos de procedência dos artigos encontrados no período de 2010 a 2014. Os dados foram coletados entre dezembro de 2014 e fevereiro de 2015 nas bases da Scientific Electronic Library Online, Biblioteca Virtual de Saúde e Portal de Periódicos Capes. Nos 17 textos selecionados, destaca-se a área da Enfermagem, que adota essa metodologia; Alfred Schutz predomina como orientação filosófica, seguido por Heidegger. Foram estudados temas relacionados com a mulher em 12 dos trabalhos. A maioria dos estudos não teceu reflexões sobre a pesquisa fenomenológica, atendo-se à escuta das narrativas e descrição fenomênica desvelada com uso de tematizações. As publicações nacionais são escassas e ainda não orientam suficientemente para a produção da investigação das essências.

Palavras-chave hermenêutica; metodologia; pesquisa qualitativa; filosofia.
Abstract Phenomenology as an inquiry method reveals itself as a possibility of making the relationship between the health professionals and the users of the health care system closer. This study aims to contribute to the process of philosophical appropriation of this perspective within the researches in this field. The research was conducted with the goal of analyzing the periodical scientific production related to this subject, identifying the phenomena assessed in these studies, the theoretical phenomenological perspectives adopted, as well as the fields of origin of the articles found between 2010 and 2014. The data were collected between December 2014 and February 2015 in the Scientific Electronic Library Online, Virtual Health Library ("Biblioteca Virtual de Saúde", in Portuguese) and Capes Periodical Portal ("Portal de Periódicos Capes", in Portuguese) databases. In the 17 selected articles, the prevailing field is nursing, which follows this metho-dology; Alfred Schutz is predominant as a philosophical guide, followed by Heidegger. In 12 of the works, the studied topics were related to women. Most of the studies did not provide reflections about the phenomenological research, focusing on hearing the narratives and on the phenomenal description that is revealed with the use of thematizations. The Brazilian publications are scarce, and, moreover, they do not provide enough guidance for the production of the investigation of the essences.

Keywords hermeneutics; methodology; qualitative research; philosophy. 


\section{Introdução}

A humanização e o processo de acolhimento destacados nas últimas décadas são apontados como estratégias para mudar o modelo de atenção no sistema de saúde brasileiro. São numerosas as críticas referentes à escuta e à postura de profissionais, muitas vezes descritos como prescritivos e autoritários. A pesquisa, neste sentido, se revela como fator estruturante do modelo assistencial, e a fenomenologia parece apropriada para essa finalidade, por facilitar a compreensão dos usuários do sistema pelos profissionais. A partir de uma base fenomenológica eles podem ampliar sua percepção sobre diferentes experiências, identificar como elas são vivenciadas e melhor lidar no cotidiano com esses sujeitos. Suspender a própria visão pode ser um caminho de melhor aproximação dos profissionais com os usuários do sistema de saúde.

No final do século XIX e início do XX, a fenomenologia se destacou em diferentes partes do mundo como corrente filosófica e como movimento que se opunha à objetivação de todas as coisas. Seu desenvolvimento internacional teve como loci fundamentais os Círculos de Göttingen e de Munique, na Alemanha. Nesses espaços, os autores discutiam os fenômenos humanos cognitivos e afetivos, colocando em perspectiva o desenvolvimento de estudos que aproximassem a fenomenologia da psicologia (Capalbo,1983).

Dentre os estudiosos desse movimento, Edmund Husserl, contrário ao que denominava de psicologismo, desenvolveu a fenomenologia como método para captar as coisas em sua essência, ou seja, a partir delas próprias. A sequência dessa iniciativa e a criação de uma escola fenomenológica foram marcos para o trabalho de Martin Heidegger, através de uma fenomenologia ontológica que destacava o ser do ente humano; com as discussões sobre a corporeidade conduzidas por Merleau-Ponty; e a sociologia abordada por Alfred Schutz.

A fenomenologia, como método, é um caminho ou atitude do pesquisador para acessar os a essência das coisas. Tal abordagem aponta para a exploração do que é dado no momento da experiência visando captar a sua essência. A proposta é colocar em suspensão as ideias tidas das coisas, para que estas possam se mostrar conforme a experiência original. Tal manifestação é desvelada a partir das narrativas obtidas durante conversas, e é possibilitada por dois movimentos essenciais: a redução e o vocativo (Van-Manen, 2014).

Com a suspensão daquilo que se conhece, o pesquisador descreve o fenômeno estudado livre de ideias preconcebidas. Já o vocativo assume destaque na elaboração e apresentação das narrativas e faz parte do processo reflexivo para chegar às coisas mesmas.

O aprofundamento no método fenomenológico ocorreu durante o curso de doutoramento em Saúde Coletiva na Universidade Federal de Santa Catarina, cujo foco foi desvelar fenômenos educativos em instituições hospitalares com vistas a torná-las promotoras de saúde. Isso despertou nos autores o interesse 
em levantar as pesquisas empíricas de cunho fenomenológico realizadas na área da saúde.

Nessa pesquisa foram questões norteadoras: como tem sido utilizada a fenomenologia em pesquisas de saúde no Brasil? Quais são os fenômenos estudados? Quais são os campos da saúde e modelos desenvolvidos?

Este estudo foi desenvolvido com o objetivo de analisar a produção periódica científica relacionada à temática, identificando os fenômenos examinados nesses estudos, as perspectivas teóricas fenomênicas, bem como as áreas de procedência dos artigos encontrados no período de 2010 a 2014.

\section{O percurso para a obtenção dos dados}

Pesquisa realizada no período de 8 de dezembro de 2014 a 5 de fevereiro de 2015 nas bases de dados do Portal de Periódicos da Capes, Scientific Electronic Library Online (SciELO) e Biblioteca Virtual da Saúde (BVS) nos anos de 2010 a 2014. Os termos usados para a busca dos dados estão apresentados na Figura 1.

Figura 1

Bases de dados virtuais e termos de pesquisa usados para este estudo

\begin{tabular}{|c|c|}
\hline Base de dados & Termos de pesquisa \\
\hline Portal de periódicos da Capes & $\begin{array}{l}\text { Fenomenologia da saúde; métodos } \\
\text { Fenomenologia da saúde; métodos; pesquisa qualitativa } \\
\text { Fenomenologia; pesquisa qualitativa em saúde }\end{array}$ \\
\hline $\begin{array}{l}\text { Biblioteca Virtual em Saúde } \\
\text { (BVS) }\end{array}$ & Pesquisa qualitativa em saúde; fenomenologia; métodos \\
\hline $\begin{array}{l}\text { Scientific Electronic Library } \\
\text { Online (SciELO) }\end{array}$ & Fenomenologia; métodos; pesquisa qualitativa em saúde \\
\hline
\end{tabular}

Os critérios de inclusão foram: ter utilizado a fenomenologia como método de estudo, ser resultado de pesquisa e ser da área da saúde. Excluíram-se aqueles que eram revisões bibliográficas, abordavam outros campos do saber e que não inseriam a fenomenologia como proposta investigativa. Foram critérios para evidenciar os fenomenólogos nos trabalhos: a identificação pelos autores nos títulos e resumos. Aqueles que não deixaram clara essa opção foram pré-selecionados para leitura na íntegra.

Durante as buscas bibliográficas, foram organizadas planilhas com os resultados conforme títulos e resumos, os quais subsidiaram o processo de inclusão/exclusão dos artigos a serem lidos na íntegra. Na pré-seleção, foram lidos os títulos e excluídos os repetidos e aqueles que não eram da área da saúde. Nos resumos, identificaram-se o tipo de estudo e a utilização da 
fenomenologia como método e foram descartados aqueles que não se tratavam dessa modalidade de estudo. Ainda se excluíram textos, após a leitura na íntegra, ao se verificar que se enquadravam nos critérios de exclusão. A Figura 2 mostra a síntese do processo de pesquisa e seleção dos artigos.

Figura 2

Fluxograma de síntese metodológica

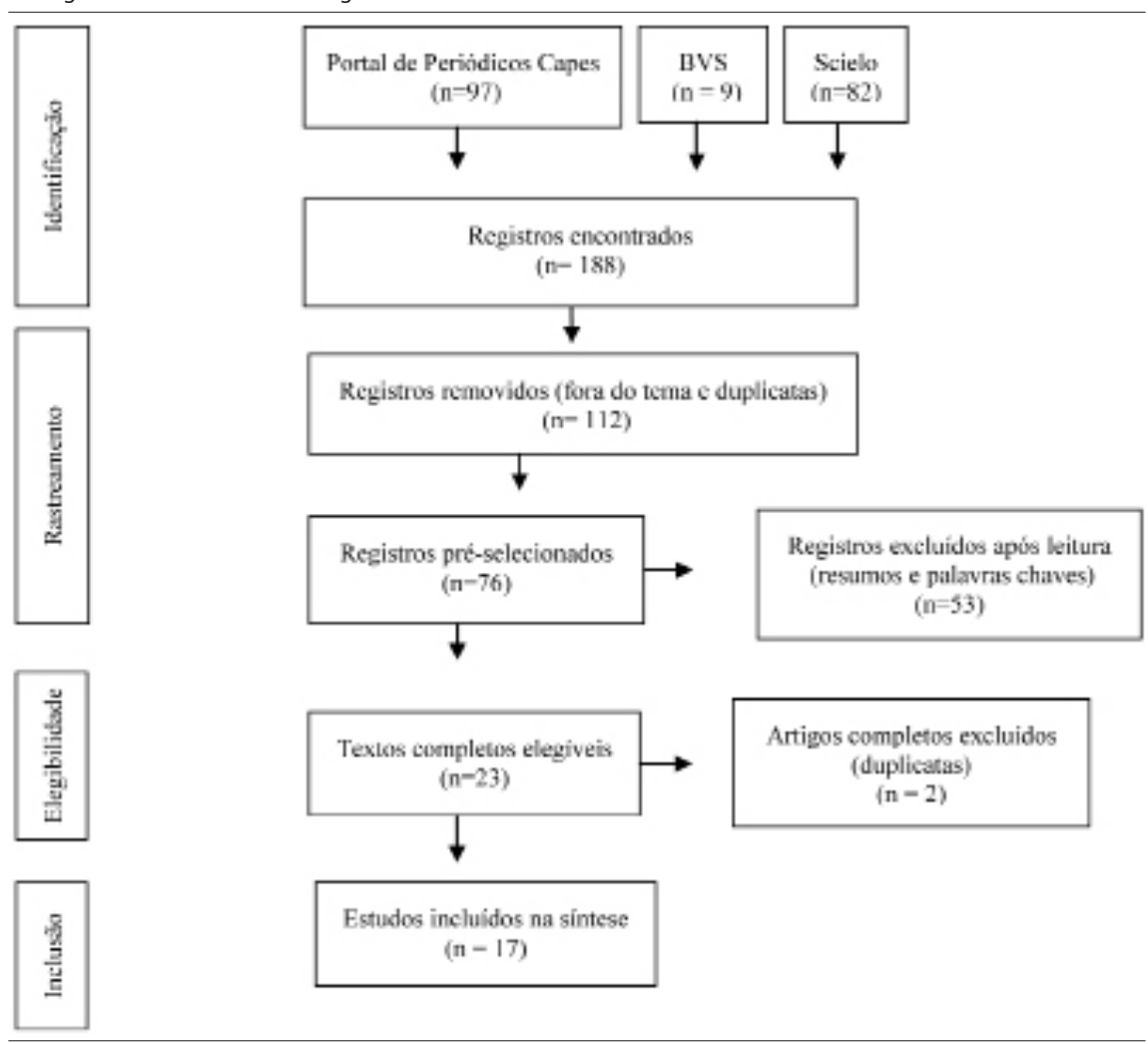

Fonte: Adaptado de Moher et al., 2009.

No Portal de Periódicos Capes, realizaram-se três buscas com diferentes combinações dos termos (Figura 1). Na primeira, foram recuperados 31 títulos; destes, 13 foram excluídos por não serem relativos ao tema; três eram repetidos e 15 foram pré-selecionados. Após a leitura dos resumos e palavras-chave, foram excluídos três registros; restaram 12 para leitura na íntegra.

Na combinação dos termos 'fenomenologia da saúde` e 'pesquisa qualitativa` foram recuperados 31 registros. Dez estavam repetidos e foram excluídos; 15 foram descartados por não serem resultados de pesquisas e ou por não serem da área da saúde. Após a leitura dos resumos, restaram seis registros.

Na terceira combinação, foram usados os termos 'fenomenologia' e 'pesquisa qualitativa em saúde' e recuperaram-se 35 registros. Excluíram-se os 25 repetidos; após a leitura dos títulos, três deles foram eliminados por não tratarem do tema. Dos sete remanescentes, após a leitura dos resumos e pa- 
lavras-chave, restaram três para leitura na íntegra. Portanto, são 21 títulos selecionados nessa base.

No portal da BVS, foram obtidos nove registros e, destes, os quatro repetidos foram excluídos; dos cinco restantes, após a leitura dos resumos e palavras-chave, excluíram-se três, restando dois textos para leitura na íntegra.

$\mathrm{Na}$ base de dados da SciELO foram obtidos 82 registros, dos quais 38 foram descartados por não serem da área da saúde e um por ser repetido; foram pré-selecionados 43 registros. Esses foram eliminados com a leitura dos resumos e palavras-chave, por não tratarem do tema, serem de outras áreas ou não terem a fenomenologia como método.

Com os levantamentos parciais e leitura dos 22 títulos, excluíram-se dois por serem duplicados; foram lidos na íntegra 20 textos. Nessa etapa, excluímos ainda outros três artigos, por não se adequarem aos critérios anteriormente descritos. Restaram 17 artigos que foram numerados sequencialmente, lidos na íntegra e tomados como base para este estudo. Os artigos foram organizados conforme título, local e ano de publicação, fenômeno estudado e filósofo de referência para desvelamento dele, método de tratamento das informações e temas de análise.

\section{Resultados dos fenômenos investigados e campos de pesquisa}

Diferentes fenômenos foram investigados em distintos campos profissionais da saúde. As publicações se concentraram em periódicos de São Paulo; uma delas foi divulgada em periódico estrangeiro. Para responder às perguntas inicialmente apresentadas, listamos na Tabela 1 os fenômenos estudados e respectivos filósofos citados como referência primordial.

Tabela 1

Artigos selecionados conforme campo de saúde, fenômeno e autor que fundamentou a pesquisa e ano de publicação

\begin{tabular}{|c|c|c|c|c|}
\hline $\mathbf{N}$ & Campo & Fenômeno & Fenomenólogo & $\begin{array}{l}\text { Ano de } \\
\text { publicação }\end{array}$ \\
\hline 1 & Nutrição & $\begin{array}{l}\text { Amamentação nos dois primeiros anos } \\
\text { de vida do bebê na ótica de nutrizes }\end{array}$ & Alfred Schutz & 2013 \\
\hline 2 & Enfermagem & $\begin{array}{l}\text { Prevenção de câncer de colo uterino em } \\
\text { gestantes e como elas se projetam em } \\
\text { relação ao tema }\end{array}$ & Martin Heidegger & 2013 \\
\hline 3 & Enfermagem & $\begin{array}{l}\text { Diálise peritoneal na experiência vivida } \\
\text { por pacientes portadores de insuficiência } \\
\text { renal crônica. }\end{array}$ & Paul Ricouer & 2012 \\
\hline 4 & Enfermagem & $\begin{array}{l}\text { Mulheres em situação de ser mãe e } \\
\text { professoras }\end{array}$ & Alfred Schutz & 2011 \\
\hline
\end{tabular}


Tabela 1 - continuação

\begin{tabular}{|c|c|c|c|c|}
\hline $\mathbf{N}$ & Campo & Fenômeno & Fenomenólogo & $\begin{array}{l}\text { Ano de } \\
\text { publicação }\end{array}$ \\
\hline 5 & Enfermagem & $\begin{array}{l}\text { Necessidades de cuidados das mulheres } \\
\text { infectadas pelo Papilomavírus }\end{array}$ & Martin Heidegger & 2012 \\
\hline 6 & Enfermagem & $\begin{array}{l}\text { A mulher idosa, suas necessidades e } \\
\text { expectativas }\end{array}$ & Alfred Schutz & 2013 \\
\hline 7 & Enfermagem & $\begin{array}{l}\text { A intenção da ação social dos docentes } \\
\text { enfermeiros e docentes de outras áreas } \\
\text { da saúde de um Curso de Graduação em } \\
\text { Enfermagem }\end{array}$ & Alfred Schutz & 2010 \\
\hline 8 & Enfermagem & Cuidado com o idoso de 80 anos ou mais & Martin Heidegger & 2012 \\
\hline 9 & Enfermagem & $\begin{array}{l}\text { Procura precoce de serviço hospitalar por } \\
\text { gestantes no final da gestação }\end{array}$ & Alfred Schutz & 2011 \\
\hline 10 & Saúde pública & $\begin{array}{l}\text { Apoio de profissionais de saúde das } \\
\text { unidades básicas para mulheres durante } \\
\text { a amamentação }\end{array}$ & Martin Heidegger & 2010 \\
\hline 11 & Medicina & $\begin{array}{l}\text { Influência do modelo biomédico e da } \\
\text { mídia na representação social da dor } \\
\text { durante o trabalho de parto }\end{array}$ & Serge Moscovici & 2011 \\
\hline 12 & Nutrição & $\begin{array}{l}\text { Experiência de adolescentes do sexo } \\
\text { feminino com transtornos alimentares }\end{array}$ & Amedeo Giorgi & 2010 \\
\hline 13 & Enfermagem & $\begin{array}{l}\text { Atuação profissional de enfermeiros e suas } \\
\text { expectativas sobre o desenvolvimento da } \\
\text { gestão do cuidado integral }\end{array}$ & Alfred Schutz & 2013 \\
\hline 14 & Enfermagem & $\begin{array}{l}\text { Mães vivenciando a gravidez da filha } \\
\text { adolescente }\end{array}$ & Alfred Schutz & 2012 \\
\hline 15 & Enfermagem & $\begin{array}{l}\text { Processo de morte/morrer e luto para a } \\
\text { pessoa idosa }\end{array}$ & Martin Heidegger & 2014 \\
\hline 16 & Enfermagem & $\begin{array}{l}\text { Encontrar os motivos de denúncia de } \\
\text { parceiros devido à violência com suas } \\
\text { companheiras }\end{array}$ & Alfred Schutz & 2012 \\
\hline 17 & Enfermagem & $\begin{array}{l}\text { O típico das mulheres denunciantes de } \\
\text { violências de parceiros }\end{array}$ & Alfred Schutz & 2011 \\
\hline
\end{tabular}
Fonte: Os autores.

Dos 17 textos, 13 são pesquisas na área da enfermagem, das quais duas são relativas ao ensino. Dois artigos foram produzidos na nutrição; um trabalho é da área da saúde pública e outro da medicina. O referencial mais utilizado foi a fenomenologia sociológica de Alfred Schutz, em nove trabalhos, e a fenomenologia ontológico-existencial de Martin Heidegger, em cinco. Também aparecem estudos que se fundamentaram na fenomenologia hermenêutica de Paul Ricouer, na representação social de Serge Moscovici e na fenomenologia descritiva de Amedeo Giorgi. 
Os fenômenos estudados abordaram saúde e doença em seus aspectos preventivos e de cuidado, bem como situações de violência de parceiros. Também a vivência profissional no ensino de graduação e situações limitantes da vida humana, como lidar com seu início e seu final. A publicação dos artigos se centrou nos anos de 2012 (5), 2011 (4), e 2013 (4).

Na Tabela 2, são apresentados os locais onde as pesquisas foram desenvolvidas, e as opções para a coleta e análise descritiva dos fenômenos.

\section{Tabela 2}

Distribuição dos artigos selecionados conforme local de pesquisa e opções metodológicas para análise de dados

\begin{tabular}{|c|c|c|}
\hline $\mathbf{N}$ & $\begin{array}{l}\text { Local da } \\
\text { pesquisa }\end{array}$ & Opções metodológicas de análise de dados \\
\hline 1 & Bahia & $\begin{array}{l}\text { Análise temática proposta por Minayo para a organização em categorias; seleção de } \\
\text { unidades de significado removendo o texto em torno de cada unidade guia. }\end{array}$ \\
\hline 2 & Bahia & $\begin{array}{l}\text { Análise fundamentada na hermenêutica da facticidade. Para proceder à redução, as falas } \\
\text { foram dispostas em papel e extraídos delas elementos ônticos: ansiedade, medo, silêncio, } \\
\text { falta de informação, falta de entendimento, insegurança e descrença na relação conjugal. } \\
\text { Também os elementos ontológicos: ser-com, solicitude, encobrimento, pré-ocupação, } \\
\text { ambiguidade e cuidado inautêntico. Na construção, foi investigado como as mulheres } \\
\text { entendem o momento e como elas se projetam em relação à prevenção; na destruição, } \\
\text { a verdade ôntica e ontológica apareceram fundamentadas na observação do ser e em } \\
\text { entidades da fenomenologia existencial do filósofo. }\end{array}$ \\
\hline
\end{tabular}
a partir de conceitos de intersubjetividade, mundo social, ação social, situação biográfica, bagagem de conhecimentos e tipificação. das unidades convergentes para a tematização. conhecimentos, intersubjetividade, motivação e tipificação para a análise compreensiva. Elaboração de categorias que expressavam os motivos das ações dos narradores. e o hermenêutico, para desvelar o sentido do ser que se mostra na análise compreensiva; e elaboração das unidades de significado. 
Tabela 2 - continuação

\begin{tabular}{|c|c|c|}
\hline $\mathbf{N}$ & $\begin{array}{l}\text { Local da } \\
\text { pesquisa }\end{array}$ & Opções metodológicas de análise de dados \\
\hline 10 & $\begin{array}{l}\text { Rio de } \\
\text { Janeiro }\end{array}$ & $\begin{array}{l}\text { Uso de dois momentos metódicos: constituição dos significados em estruturas de } \\
\text { significação (compreensão vaga e mediana), nos quais se faz a redução; segundo } \\
\text { momento é constituído de interpretação do que foi desvelado. A frequência das unidades } \\
\text { de significação foi considerada para estabelecer novas unidades de significação. }\end{array}$ \\
\hline 11 & $\begin{array}{l}\text { Santa } \\
\text { Catarina }\end{array}$ & $\begin{array}{l}\text { Tematização a partir de Minayo, com análise fundamentada na teoria da representação } \\
\text { social do filósofo em pauta. }\end{array}$ \\
\hline 12 & $\begin{array}{l}\text { Santa } \\
\text { Catarina }\end{array}$ & $\begin{array}{l}\text { Transformação das unidades em linguagem psicológica e síntese das unidades } \\
\text { de significado. }\end{array}$ \\
\hline 13 & Uruguai & $\begin{array}{l}\text { Agrupamento de aspectos significativos nos depoimentos para compor as categorias } \\
\text { e análise para a compreensão do fenômeno. }\end{array}$ \\
\hline 14 & Paraná & $\begin{array}{l}\text { Desenvolvimento dos passos propostos pela fenomenologia social; leitura e releitura para } \\
\text { apreensão global do sentido; identificação e agrupamento de aspectos significativos das } \\
\text { narrativas; elaboração de categorias; busca dos motivos para e dos motivos por quê. }\end{array}$ \\
\hline 15 & Bahia & $\begin{array}{l}\text { Dois momentos metódicos: a constituição dos significados em estruturas de significação } \\
\text { (compreensão vaga e mediana), em que se faz a redução; e interpretação do desvelado. }\end{array}$ \\
\hline 16 & $\begin{array}{l}\text { Rio Grande } \\
\text { do Sul }\end{array}$ & $\begin{array}{l}\text { Escuta e transcrição das entrevistas; leitura dos textos e agrupamento de falas } \\
\text { conforme a existência de ideias comuns. Na sequência, fizeram recortes nas falas } \\
\text { que respondiam a pergunta de pesquisa; captaram os motivos para denunciar e } \\
\text { fizeram releitura do texto em sua íntegra para confirmar as categorias elaboradas; } \\
\text { identificação das relações das categorias entre si e conclusão do típico da ação. }\end{array}$ \\
\hline 17 & $\begin{array}{l}\text { Rio Grande } \\
\text { do Sul }\end{array}$ & $\begin{array}{l}\text { Escuta e transcrição das entrevistas; leitura dos textos na íntegra e agrupamento de } \\
\text { falas de acordo com a existência de ideias comuns. Foram feitos recortes nas falas que } \\
\text { respondiam a pergunta de pesquisa; na sequência, as autoras focalizaram os motivos } \\
\text { de mulheres para denunciar violências. Ao final, esse material foi relido na íntegra para } \\
\text { confirmar as categorias construídas e identificação das relações das categorias entre si, } \\
\text { para a conclusão do típico da ação. }\end{array}$ \\
\hline
\end{tabular}

Fonte: Os autores.

A coleta de dados ocorreu nos estados de São Paulo e Bahia, com quatro pesquisas em cada um. Em Santa Catarina e no Paraná, foram conduzidos quatro estudos, dois por estado. Duas pesquisas publicadas se referem à coleta de dados no Rio Grande do Sul. Nas outras três pesquisas, os dados foram coletados em Minas Gerais, Rio de Janeiro e no Uruguai, uma em cada das áreas geográficas.

Conforme mostrado na Tabela 2, a análise fundamentada em aspectos da fenomenologia social de Schutz foi afirmada nos artigos 4, 6, 7, 14, 16 e 17; não foram citados filósofos nos artigos 3, 5, 9,12 e 13. A hermenêutica filo- 
sófica de Heidegger fundamentou os trabalhos de número 2, 8,10 e 15; e, em dois trabalhos, autoras usaram elementos da pesquisa social, propostos por Minayo (1 e 11).

\section{Caminhos para compreender o fenômeno}

A população participante dos estudos variou de sete até 480 pessoas, exclusivamente mulheres em dez trabalhos. Em seis pesquisas, os autores limitaram o número de participantes pela saturação de informações. Nos outros trabalhos, foram definidos como fatores de inclusão/exclusão estar doente ou ter diagnóstico, faixa etária e possibilidade de estabelecer comunicação verbal. A participação foi condicionada à idade e à assinatura de termo de consentimento livre e esclarecido.

Quanto ao método de levantamento de informações, os autores se fundamentaram em entrevistas realizadas em diferentes locais. Nos 17 trabalhos, houve um encontro para a entrevista; em 16 dessas pesquisas, as entrevistas foram gravadas; na outra, o autor anotou as respostas durante o relato dos respondentes. No estudo 9, os autores relataram o uso da entrevista semiestruturada, e nos artigos 2, 8, 15, 16 e 17 foi empregado o termo 'entrevista fenomenológica'. Em nove pesquisas as entrevistas foram realizadas em serviços de saúde ou de cuidado e em locais onde o participante registrou sua demanda; em outras duas, optou-se pela residência dos participantes. Em seis trabalhos, os autores informaram que o horário e o local foram escolhidos pelos participantes.

Em um dos estudos, questionou-se o que os entrevistados esperavam de ações de profissionais relativas ao cuidado; outro perguntou sobre ações no ensino. No artigo 9, as autoras não mencionaram a pergunta de suas entrevistas semiestruturadas; os demais colocaram questões norteadoras para obter as narrativas.

Com relação ao tratamento dos dados obtidos, a opção por análise temática após várias escutas e ou leitura das transcrições foi o procedimento de escolha naqueles trabalhos que optaram pela gravação. A partir daí, foram organizados os temas como mostra a Tabela 2.

Desenvolvidas as etapas metodológicas fundamentadas nas narrativas, o agrupamento por convergências foi a escolha da maioria dos pesquisadores para a elaboração de categorias de análise ou tematização. As unidades temáticas estão listadas na Tabela 3. 
Tabela 3

Distribuição dos artigos e temas desenvolvidos no processo de desvelamento do fenômeno

N Temas elaborados

1 Singularidades da experiência da amamentação nos primeiros dois anos da criança; suporte familiar e de profissionais de saúde; a importância da amamentação para a saúde e nutrição do bebê e da mãe.

O velamento da palavra câncer: medo da doença e da morte? Inautenticidade na relação entre profissionais de saúde e pacientes: o impacto da prevenção de câncer cervical em gestantes; expressões de solicitude e ser-com na relação gestante e feto; tagarelice: o que acontece com a gestante durante a prevenção do câncer cervical.

3 O confronto com o universo da falência renal e do tratamento dialítico; a vivência das mudanças no próprio corpo; fontes de apoio.

4 Dificuldade no desempenho de múltiplas atividades; cuidado de si mesma e conciliação dos papéis sociais.

5 A busca do cuidado como solicitude.

6 Motivos por que: autonomia, família e limitações; motivos para: necessidades de cuidado.

7 Motivos para - categorias: o aluno como futuro profissional, o crescimento pessoal do aluno, o docente como pesquisador, os conteúdos.

8 A vivência do o cuidado de si; a compreensão da necessidade de cuidado do outro e a experiência de ser cuidado pelo outro: familiar ou não.

9 Por apresentar sinais ou sintomas diferentes dos que sentiram ou sobre os quais foram informadas; por identificar o trabalho prévio com o verdadeiro trabalho de parto; medo associado a possíveis complicações fetais por aproximar-se a possível data do parto; por se sentir mais tranquila com a assistência de profissionais da instituição; pela incapacidade de outros serviços para resolver o seu problema; por medo da ocorrência do parto extra-hospitalar; por buscar tranquilidade no parto na tentativa de modificar o comportamento.

10 Estruturas de significação quanto ao apoio para amamentar: nenhum apoio, apoio dúbio, apoio como incentivo, apoio no manejo, apoio como parceria. Estruturas de significação quanto às sugestões sobre como a unidade de saúde poderia ajudá-las a amamentar: apoio no manejo, apoio como parceria, apoio continuado, sem sugestão.

11 Categorias empíricas: medos e preocupações, experiência e influência sociocultural. Categorias interpretativas: modelo biomédico, falta de informação e papel da mulher na decisão sobre o tipo de parto.

12 O que representa a comida; hábito alimentar; alimentos que deixaram de ser consumidos; alimentos que passaram a ser consumidos; consumo de refrigerantes; escolhas alimentares; composição das refeições; hábito alimentar da família; alimentação saudável.

13 Motivos por que: a teoria e a prática; sobrecarga administrativa; busca pelo conhecimento; insegurança. Motivos para: definições específicas; autonomia e identidade profissional e valorização da profissão.

14 Reação à gravidez; suporte oferecido à filha.

15 A autenticidade e a inautenticidade do ser para a morte.

Distribuição dos artigos e temas desenvolvidos no processo de desvelamento do fenômeno

16 Apreender os 'motivos para` da mulher que denuncia seu vivido em situação de violência.

17 Apreender o típico da ação de mulheres que denunciam o vivido da violência.

Fonte: Os autores. 
Conforme a Tabela 3, a tematização das narrativas fundamentadas na perspectiva de Schutz foram relativas aos papéis sociais desenvolvidos (4); motivos por que e motivos para foram descritos Segundo as respostas dadas $(6,7,13,14$, e 16), bem como a conduta típica de ações dos participantes (17).

Interpretadas sob a ótica heideggeriana, os estudos apresentaram o desvelamento de fenômenos encobertos em função da ocupação e das estruturas ontológicas do ser humano no mundo $(2,8,15)$ e estruturas de significação (10). Os demais textos $(3,5,9$ e 12) apresentam estruturação temática não relacionada com a fenomenologia.

\section{A fenomenologia como fundamento da pesquisa em saúde}

A fenomenologia como método de pesquisa se fundamenta na postura do pesquisador, que se abstém do conhecimento prévio do fenômeno com a finalidade de explorar a forma como os sujeitos experimentam eventos vivenciados. Método, aqui, refere-se a um percurso ou atitude para aproximação com o fenômeno estudado, enquanto abster-se implica colocar em suspensão teorias, suposições e emoções de que se tem conhecimento. Busca-se apresentar a vivência tal qual ela foi compreendida na consciência pré-reflexiva, isto é, a experiência originária, antes de tematizar e nomear com base nos conhecimentos advindos da ciência e do viver cotidiano do pesquisador (Van-Manen, 2014).

A reflexão e a análise fenomenológica ocorrem na atitude da epoché, que significa colocar entre parênteses; suspender provisoriamente qualquer juízo. Essa atitude conduz para a redução propriamente dita, que é restringir-se ao fenômeno vivenciado. É necessário que o pesquisador se dedique, para, no contato direto com o fenômeno, ver o que é dado na experiência sem ideias preconcebidas (Giles, 1975; Van-Manen, 2014).

A abordagem fenomenológica, as formas de conduzir a redução, as propostas diversas de análise de dados, são distintas para diferentes autores, como mostrado na Tabela 2. Segue-se a apresentação, de forma sucinta, e, para compreensão desta discussão, das abordagens preconizadas pelos autores de referência mais frequentes nos artigos selecionados: Alfred Schutz e Martin Heidegger.

Alfred Schutz desenvolveu a fenomenologia das relações sociais ao fazer dialogarem os escritos de Edmund Husserl com os de Max Weber. Nas relações sociais existe um mundo intersubjetivo que é compartilhado com os semelhantes de modo a tornar reduzido o espaço para a subjetividade individual. Esse mundo compartilhado é tipificado em suas ações, o que torna viável a um observador compreender determinados movimentos a partir do que é aceito naquela comunidade como situação típica (Wagner, 1970). 
Nas situações pragmáticas, a atitude natural em que vive o indivíduo é limitante para a busca de conhecimentos claros, lógicos e sistemáticos, já que ele valoriza mais aqueles rotineiros, do dia a dia. Dessa forma, tanto o mundo quanto as coisas são interpretadas conforme o grupo cultural internalizado, o qual forma uma concepção relativamente natural do mundo, alicerçada nas tipificações - estratégias de reconhecimento - constituídas desde a infância. As tipificações são a base da interpretação das experiências e são necessárias para a manutenção da comunicação, por meio da linguagem e da cultura. Embora as tipificações se relacionem com o mundo social, cada ser tem sua biografia, sua subjetividade (Wagner, 1970; Macedo e Boava, 2012).

Os homens, apesar de diferentes, têm comportamentos típicos do grupo social do qual participam e, para compreender os atos uns dos outros, é preciso conhecer os 'motivos por que' de tais atos. Isso demandaria vivenciar o eu do outro em sua singularidade, o que não é possível. Diante disso, avaliar conforme os 'motivos por que', conforme a tipicidade, é o caminho. Por outro lado, para compreender as coisas sociais, é preciso desvelar os 'motivos a fim de', imaginando-se no mundo social do outro e agindo com os seus mesmos 'motivos a fim' (Wagner, 1970; Castro, 2012).

As tipificações são um sistema social de interpretação de situações comuns e suas relevâncias no grupo. Por pertencer a vários grupos, o homem tem, em sua personalidade, interesses privados. A sua escolha por seguir ou não determinada tipificação guarda proximidade com a sua hierarquia privada de relevâncias (Wagner, 1970). Independente da tipificação, o homem pode tomar para si a responsabilidade de agir diferente, tendo por base os seus 'motivos por que' e 'motivos para'. O que lhe resta: assumir sua escolha.

Sobre a fenomenologia ontológica, destaque-se que Martin Heidegger desenvolveu a hermenêutica da facticidade com base em interrogações sobre o ser do humano, mostrando que este era tratado como coisa entre coisas. Para isso, afirma que o ser humano mundano é constantemente tolhido de seu contato consigo próprio, já que em seu cotidiano vive de forma inautêntica, de modo inconsciente. Isso graças aos aspectos da modernidade que o torna sempre muito ocupado com as coisas e com os outros humanos, de modo a não se observar (Luijpen, 1973; Safransky, 2000; Inwood, 2002).

Dessa forma, o ser do humano, o qual ele nomeia de Dasein (ser-aí), revela diferentes modalidades do seu ser junto aos demais 'ser-aí' e as coisas: 'sercom', 'ser-junto', 'ser-em-si' e 'ser-para-a-morte'. O ser do humano descobre as coisas do mundo durante a sua utilização, e, após o uso, elas deixam de ter significado, estão aí no como dadas. Ele se ocupa delas. Já com os outros humanos, Dasein se preocupa com o ser deles, buscando compreendê-los e auxiliá-los em suas escolhas para que possam descobrir-se autenticamente (Schmidt, 2012; Kahlmeyer-Mertens, 2015). 
Entretanto, ao se ocupar das coisas de modo superficial, as suas trocas com os outros humanos giram em torno de temas supérfluos, a conversa fastidiosa da fofoca, a qual é nomeada de tagarelice; tem a ver com a conversação que o ser desenvolve no seu cotidiano com os demais. Nela se trata de assuntos irrelevantes e sem profundidade, admite o filósofo, referindo-se à superficialidade das relações mantidas entre os seres humanos que se fundamentam num modo inautêntico de viver (Safransky, 2000; Inwood, 2002).

Esse é um dos contextos que distancia o humano de experimentar a angústia, elemento que o faz rever suas atitudes e projetar-se para si mesmo. É graças à angústia que o 'ser-aí' estranha o mundo e sua vivência nele, sua falta de projetos. É um dos momentos que Dasein se compreende como 'serpara-a-morte'. Com isso, ele desenvolve a culpa em decorrência de suas escolhas identificadas com elementos não próprios ao seu eu. Passada a angústia, ele se projeta para o futuro no intuito de cuidar de sua vida, apropriando-se daquilo que se lhe apresenta e consciente de que, embora o mundo seja condicionado faticamente, não há determinação de impessoalidade (Schmidt, 2012; Kahlmeyer-Mertens, 2015).

Para Heidegger, o cuidado é um modo de ser ontológico de Dasein, que se desvela quando o ser humano compreende a sua finitude e que seu modo de ser inautêntico o distancia de fazer projetos realísticos. Ele assume então o cuidado com a sua vida, definindo projetos conscientes para seu 'estar-nomundo'. Também reflete na sua possibilidade de compreender as coisas e os outros seres humanos de modo autêntico, e não no que é dado. Logo, Dasein cuida de seu ser, cuja vida está em jogo, se ocupa das coisas, e se preocupa com os humanos. Solicitude é um elemento do modo de ser do Dasein como cuidado ao se relacionar com os seus pares, pois se preocupa para que estes se tornem também conscientes de seu ser autêntico, de forma a não depender dos demais (Luijpen, 1973; Inwood, 2002; Martins, 2013).

Na vida cotidiana, o ser humano pode escolher por viver o seu próprio ser de modo autêntico ou inautêntico, e a angústia o conscientiza de sua finitude. Como se mostrou: o ser humano é um 'ser-para-a-morte'. E aqui também ele pode escolher por ser autêntico, aceitando-a e lidando com ela, ou inautêntico, tentando escapar a essa realidade: fuga sabidamente impossível (Luijpen, 1973; Schmidt, 2012).

Destaque-se que essa compreensão da vida fática do homem e do mundo pelo 'ser-aí' ocorre por meio de três estruturas: a visão, a posição e a concepção prévias. A posição prévia se relaciona com a contextualização da qual se destaca o fenômeno a ser compreendido; na visão prévia, as qualidades do fenômeno são mediante a abstração das dos demais seres, para ser predicado apenas do ser que se quer compreender. É na concepção prévia que se formam os conceitos. Para concretizar a hermenêutica da facticidade, Heidegger afirma ser necessário desconstruir conceitos oriundos da metafísica e romper 
com posições tradicionais e, a partir daí, construir outros elementos para compreender o mundo, os entes e o 'ser-aí' fenomenologicamente (Schmidt, 2012; Gadamer, 2014; Kahlmeyer-Mertens, 2015).

Com relação aos resultados nessa pesquisa, alguns autores relataram o uso de métodos propostos pelos filósofos e, em um deles, a autoria afirmou ter usado o método da fenomenologia ontológica. Tais afirmações não se fundamentam em colocações dos filósofos, uma vez que não se advoga passos para se alcançar o fenômeno em si. Heidegger e Schutz não propuseram nenhum método, contrariamente ao afirmado em dois trabalhos.

Nos estudos, notou-se certa confusão entre o cuidado heideggeriano e o cuidado nas profissões de saúde, abordados nos artigos levantados nessa pesquisa. A compreensão vaga e mediana se refere àquela compreensão do que está dado na cotidianidade, sem reflexão e de modo impessoal, e não a um método específico da pesquisa fenomenológica (Inwood, 2002; Van-Manen, 2014).

Nos artigos que tiveram Schutz como fenomenólogo de escolha para análise, verificou-se a identificação de papéis sociais (4), de 'motivos por que' e para posturas assumidas na família (6), no ensino com acadêmicos de enfermagem (7), de gestantes, no final da gestação, para buscar por serviços assistenciais mesmo antes de entrar em trabalho de parto (9), e o vislumbrar o cuidado integral por professores do ensino de graduação em enfermagem como foco do ensino (13). Atitudes de mulheres vivenciando a situação de gravidez de sua filha adolescente indicam que há um modo de comportar-se tipicamente aceito naquele meio (14) ou ainda condutas das mulheres em relação a seus parceiros devido à violência doméstica $(16,17)$.

O emprego da fenomenologia de Schultz é característica de pesquisas que buscam compreender fenômenos vivenciados individualmente e localizá-los como típicos de determinado contexto social. Algumas vezes, as ações são motivadas por sua aceitação no grupo ou por razões pessoais. A discussão sobre a bagagem cultural e a situação biográfica que leva o feminino a estabelecer limites para situações de violência doméstica, opondo-se às hierarquias legitimamente estabelecidas no mundo sociocultural, são apresentadas nos estudos 16 e 17 .

Também essa biografia e bagagem cultural moldam projetos e atitudes de docentes de enfermagem no ensino de graduação em enfermagem; na situação de trabalhadoras e mães e a ação de mulheres que deram suporte à gestação de sua filha adolescente $(4,13,14)$. Da mesma forma, mulheres amamentam seus bebês durante os dois primeiros anos em virtude dos constructos coletivos (1).

A intersubjetividade e a bagagem cultural foram evidenciadas para compreender a necessidade de cuidados da mulher idosa (6) e motivos que levam gestantes, no final da gravidez, a buscar um serviço hospitalar mesmo não estando em trabalho de parto. Esses tiveram como motivadores as vivências, valores e crenças socialmente difundidos. 
Martin Heidegger foi referência para desvelar os significados atribuídos por gestantes ao realizar o exame preventivo de câncer de colo uterino: o medo da palavra câncer, especialmente originado das diferentes informações disponibilizadas pelos profissionais e mídia (2). O diagnóstico de doença venérea (5) leva à necessidade de suporte da família, amigos e de profissionais de saúde; em alguns momentos, a solicitude desses profissionais para ouvir a mulher, dar informações e fazer encaminhamentos não foi evidenciada. Nessas condições ocorre a inautenticidade do Dasein.

Na perspectiva de idosos de 80 anos e mais, o cuidado é compreendido como cuidar de si autonomamente ou ainda ser cuidado por alguém, seja ou não da família. O diálogo dos profissionais de saúde nas unidades básicas fortalece o apoio e esclarece dúvidas de mulheres quanto à amamentação do bebê $(8,10)$.

Por outro lado, o medo e a fuga da finitude para longevos são formas de manter a ilusão da imortalidade ou ainda a condição para vislumbrar o seu potencial para desenvolver o 'poder-ser' mais próprio. Desse modo, é possível se antecipar à morte, no sentido de aceitar a sua facticidade como ente humano. Algumas vezes, o ser se esconde, ao se manifestar no modo esconder-se no impessoal, mesmo depois de reconhecer a existência da morte, e passa a se projetar com relação a filhos e netos $(8,15)$.

A fenomenologia se mostra aberta e se relaciona com a postura fenomenológica do investigador. No meio acadêmico, sob a influência de escolas e profissões específicas, foram estruturadas metodologias para a análise das narrativas segundo os seus interesses. A exemplo, Amedeo Giorgi (apud VanManen, 2014), psicólogo de formação, que propôs etapas para a fenomenologia aplicada combinando métodos fenomenológicos com a empiria fundamentada em métodos das ciências sociais.

Conforme Giorgi, a redução envolve quatro etapas: leitura de toda a descrição para se chegar ao senso geral; retorno ao início das descrições com releitura, focalizando o fenômeno, em que são localizadas unidades de significação. Na sequência, o pesquisador deve interrogar as unidades de significação e transformá-las em linguagem psicológica, e finalizar com a síntese das unidades significativas (Coppe, 2001; Van-Manen, 2014).

O que se observa é que a autoria (12) relata o uso das etapas de Giorgi somadas às proposições de estudo de pós-graduação lato sensu, repetindo-as com base na dissertação de mestrado. Isso mostra certa confusão no entendimento e condução da pesquisa fenomenológica (Coppe, 2001; Van-Manen, 2014).

Por sua vez, Moscovici (2007) desenvolveu a teoria das representações sociais, da corrente de pensamento sociopsicológico, cujo enfoque foi explicar e prever comportamentos sociais historicamente (Jesuino, 2014; Flores et al., 2014). Nessa perspectiva, o estudioso não é referência para a fenomenologia. No estudo 11, embora as autoras o apresentem como um estudo fenomenológico, 
não são apresentados aspectos desse tipo de pesquisa; da mesma forma, a coleta e a abordagem de narrativas também não segue a proposta da fenomenologia.

Já Paul Ricour discute a compreensão do ponto de vista epistemológico, opondo-se à proposição ontológica heideggeriana. Para ele a interpretação primeira não pode ser tomada a princípio como verdade, é necessária a interpretação dos sentidos escondidos no aparente. No processo hermenêutico, é preciso considerar a relação temporal entre o presente do intérprete e o passado daquilo que é interpretado, que interfere na compreensão. São sempre dois mundos confrontados: o da obra e o do intérprete; ambos necessitam ser refletidos. Dessa maneira, há certo apagamento do intérprete; dá-se lugar ao texto para que ele se mostre e conduza quem interpreta na localização daquilo que lhe é estranho, resultando na transformação de ambos (Capalbo, 1983; Gagnebin, 1997).

Notou-se que as narrativas contidas nos artigos não apresentam o 'como' fenomenológico nem tecem considerações sobre o tratamento dado às narrativas, o que é essencial na pesquisa fenomenológica.

Os métodos das ciências sociais auxiliam na coleta de informações na pesquisa fenomenológica e passam por rearranjos para que isso ocorra. As entrevistas desenvolvidas em profundidade se mostram próprias para o desvelamento do fenômeno, e a entrevista fenomenológica apresenta essas características. Quando conduzidas como uma conversa, as informações fluem naturalmente e o entrevistador pode direcioná-la considerando o foco do estudo. Em pesquisa fenomenológica, tão importante quanto a conversa, captar o que é dado e o 'como' da experiência são essenciais (Ranieri e Barreira, 2010; Britto Junior e Feres Junior, 2011; Van-Manen, 2014).

A entrevista fenomenológica precisa ser conduzida em mais de um encontro, embora a literatura especializada afirme que o número é limitado ao desvelar-se do fenômeno. É indicado que elas sejam guiadas por perguntas abertas e organizadas por temas. Destaque-se que não há delimitação prévia do número de participantes, mas há a orientação de que o desvelamento do fenômeno indica o momento de encerrá-las (Boemer, 1994; Espitia, 2000; Van-Manen, 2014).

Dos artigos levantados, cinco mencionaram o uso da entrevista fenomenológica. No estudo 2, a abordagem do fenômeno com base em questões sobre 'o que entende e como compreende' a importância do fenômeno não permitiu entender claramente a relação com o objetivo de interpretar a experiência em si. Nos trabalhos 8 e 15, foi questionado o 'como' fenomenológico, que possibilita compreender o fenômeno. A discussão no campo é ainda se entrevistas semiestruturadas são próprias ou impróprias para o desvelamento do fenômeno, especialmente quando conduzidas em um único encontro.

As entrevistas foram realizadas em um único encontro nos 17 trabalhos. O desvelamento, nestes casos, requer uma relação de empatia e aproximação 
entre os sujeitos entrevistados e entrevistadores. Seria interessante que em trabalhos com uso de método fenomenológico este aspecto fosse explorado, o que não ocorreu nos artigos estudados.

Outro problema a ser considerado no avanço do uso do método fenomenológico em pesquisa diz respeito ao uso de saturação para estabelecer o número de entrevistados. Este procedimento pode descaracterizar a pesquisa fenomenológica e possibilita argumentar se houve coleta de dados com a profundidade necessária para desvelar os fatos estudados. O número de entrevistados em dois trabalhos, 45 e 480 respectivamente, também pode causar estranheza no âmbito da fenomenologia. Em um dos trabalhos, os autores demandaram que as respostas, transcritas em concomitância com o diálogo, ocupassem de uma a duas linhas. Ficam muitas dúvidas sobre se trabalhos desta natureza podem legitimamente ser entendidos como pesquisa fenomenológica.

A análise interpretativa na pesquisa fenomenológica é feita com base na redução e no vocativo. A redução se constitui didaticamente de duas posturas do pesquisador: a epoché e a redução propriamente dita. A epoché implica suspender o que se sabe para interpretar a narrativa; na redução, são recomendadas leituras atentas dos textos sobre o fenômeno que se quer compreender, chegando-se à tematização (Van-Manen, 2014).

O método filosófico para a apresentação do fenômeno é chamado de vocativo, uma dimensão ativada principalmente na redação do texto fenomenológico. Van-Manen (2014) afirma que por meio dele o pesquisador desenvolve a análise e expressa aspectos não cognitivos do fenômeno; a descrição da experiência vivenciada é trazida para a presença de modo a criar, no pesquisador e no leitor, a sensação de proximidade no tempo e espaço sobre o que está sendo apresentado, de modo que possam 'viver' o que está sendo narrado, com emoções próprias da situação.

Dentre as formas de se desenvolver o método, citamos as pequenas histórias, o revocativo e a proximidade. Nesta última, desenvolve-se uma conversa com o leitor de modo a seduzir sua atenção, organizando o texto narrativo de forma que o leitor 'veja' o fenômeno do modo como este se revela no sentido experiencial (Van-Manen, 2014).

O uso de pequenas histórias elaboradas a partir da conversa com o sujeito da pesquisa é outra possibilidade de apresentação do fenômeno estudado, destaca Van-Manen. A elaboração da história propicia refletir sobre o vivido e apropriar-se da experiência, sendo a sua própria organização espaço para a reflexão fenomenológica. Essa história pode ser desenvolvida especialmente nos casos em que o participante não fornece a narrativa completa de uma vivência, mesmo após repetidos encontros e tentativas de obtenção de esclarecimentos (Van-Manen, 2014).

Acrescenta o autor que o método revocativo ajuda a trazer a experiência vivida para a presença, de modo que o leitor reconheça a possibilidade da 
experiência. Revocar é trazer do passado as palavras, de forma que digam o que ocorreu nas condições anteriores ao significado linguístico da palavra. Importa a forma como o pesquisador elabora a escrita de modo que o leitor perceba a plausibilidade do que está lendo (Van-Manen, 2014).

Dos textos lidos, a leitura repetida das respostas foi utilizada para agrupamento e tematização. As abordagens metodológicas foram, entretanto, de autores não caracteristicamente ligados à fenomenologia. Sobre a forma de apresentar os relatos, registre-se a ausência do vocativo. Esse fato pode ser explicado pela recente tradução de estudos nos quais esta dimensão é apresentada.

\section{Considerações finais}

A abordagem fenomenológica em pesquisas mostra o 'como' dos objetos em sua essência. o 'como' de um fenomênico, ao ser interpretado, trata aspectos desvelados da vivência humana em sua relação com o mundo e demais sujeitos e coisas. Desvelar implica mostrar o que está encoberto, escondido. Embora a cotidianidade, na maioria das vezes, mantenha velados os modos pelos quais o ser se manifesta, todos são instados a ouvir a voz da consciência em favor de mostrar o ser que cada um é autenticamente.

Diferentes campos da saúde têm buscado evidenciar o 'como' dos objetos e entes que fazem parte da vida, com destaque, no brasil, para a enfermagem. As mulheres são os sujeitos que predominam como participantes. Dentre os fenomenólogos que mais têm alicerçado o interesse no esclarecimento desses fenômenos que atingem o universo feminino estão Alfred Schutz e Martin Heidegger.

Nas pesquisas estudadas para esse trabalho, há controvérsias entre o que se pode definir como postura fenomenológica do pesquisador e método. A primeira envolve a perspectiva do investigador ao longo do desenvolvimento da pesquisa, tratamento e análise das narrativas. Já o método é a opção metodológica do autor para se apropriar e conhecer determinado objeto de pesquisa, segundo as concepções originais da técnica em questão que, nesse caso, advém na teoria do conhecimento.

Ainda, nas pesquisas analisadas, a fenomenologia é usada como abordagem metodológica, o que não se caracteriza como aplicação do método fenomenológico em si, isto porque, o que se observa no corpus é que os autores buscam aproximações. Logo, sua transposição a contextos que carecem desta perspectiva de análise, é válida e enriquecedora, exigindo assim, que seu uso seja adaptado aos domínios analisados.

Entende-se que a abordagem fenomenológica em pesquisa ainda carece de aprofundamento e de divulgação na literatura científica brasileira. A fenomenologia é potencialmente um ótimo meio para avançar o conhecimento 
sobre os significados existenciais humanos e, portanto, para o avanço do setor saúde no país.

\section{Colaboradores}

Rosilda Verissimo participou de todas as etapas da pesquisa: concepção, execução e redação. Walter Ferreira de Oliveira fez a revisão crítica do manuscrito e da redação.

Resumen La fenomenología como modelo de investigación se muestra como posibilidad de acercamiento entre los profesionales de la salud y los usuarios del sistema de salud. Este estudio busca contribuir con el proceso de apropiación filosófica de dicho enfoque en las investigaciones en esta área. La investigación se realizó con el objetivo de analizar la producción científica periódica relacionada a la temática, identificando los fenómenos evaluados en dichos estudios, las perspectivas teóricas fenomenológicas abordadas, así como los campos de procedencia de los artículos encontrados en el período entre 2010 y 2014. Los datos se recogieron entre diciembre del 2014 y febrero del 2015 en las bases de la Scientific Electronic Library Online, Biblioteca Virtual en Salud y Portal de Periódicos Capes relativos al período de 2010 al 2014. En los 17 textos seleccionados, se destaca el área de la enfermería que adopta esta metodología; Alfred Schutz predomina como orientación filosófica, seguido por Heidegger. En 12 de los trabajos se estudiaron temas relacionados con la mujer. La mayoría de los estudios no elaboró reflexiones sobre la investigación fenomenológica, ateniéndose a la escucha de las narraciones y descripción fenoménica puesta en evidencia con el uso de tematizaciones. Las publicaciones nacionales son escasas y además no orientan lo suficiente a la producción de la investigación de las esencias.

Palabras clave hermenéutica; metodología; investigación cualitativa; filosofía.

\section{Notas}

${ }^{1}$ Associação Educacional Luterana Bom Jesus Ielusc, Joinville, Santa Catarina, Brasil.

$<$ roverissimobustus@gmail.com>

Correspondência: Associação Educacional Luterana Bom Jesus Ielusc, rua

Princesa Isabel, 438, Centro, CEP 89201-300, Joinville, Santa Catarina, Brasil.

${ }^{2}$ Universidade Federal de Santa Catarina, Centro de Ciências da Saúde,

Departamento de Saúde Pública, Florianópolis, Santa Catarina, Brasil.

$<$ walteroliveira.ufsc@gmail.com> 


\section{Referências}

BOEMER, Magali R. A condução de estudos segundo a metodologia de investigação fenomenológica. Revista Latino-Americana de Enfermagem, Ribeirão Preto, v. 2, n. 1, p. 83-94, 1994.

BRITTO JUNIOR, Álvaro F.; FERES JUNIOR, Nazir. A utilização da técnica da entrevista em trabalhos científicos. Evidência, Araxá, v.7, n. 7, p. 237-50, 2011. Disponível em: $<$ http://www.uniaraxa.edu.br/ojs/index.php/ evidencia/article/view/200/186>. Acesso em: 2 fev. 2015.

CAPALBO, Creusa. Fenomenologia e hermenêutica. Rio de Janeiro: Âmbito Cultural, 1983.

CASTRO, Fábio F. A sociologia fenomenológica de Alfred Schutz. Ciências Sociais Unisinos, São Leopoldo, v. 48, n. 1, p. 52-60, jan.-abr. 2012. Disponível em: <http://revistas.unisinos.br/index.php/ciencias_sociais/article/ view/csu.2012.48.1.06/839>. Acesso em: 25 jan. 2016.

COPPE, Antonio A. F. A vivência em grupos de encontro: um estudo fenomenológico de depoimentos. 2001. 151f. Dissertação (Mestrado) - Universidade Federal do Rio de Janeiro, Rio de Janeiro, 2001.

ESPITIA, Edelmira C. La fenomenologia interpretativa como alternativa apropriada para estudiar los fenómenos humanos. Investigación y Educación en Enfermería, Antioquia, v. 18, n. 1, p. 27-35, mar. 2000. Disponível em <http:// www.redalyc.org/articulo.oa?id=105218294002> Acesso em: 10 out. 2014.

FLORES, Talita M. et al. Considerações sobre a teoria das representações sociais como capítulo da história da psicologia social. Boletim: Academia Paulista de Psicologia, São Paulo, v. 34, n. 87, p. 320-335, 2014.

GADAMER, Hans G. Verdade e método I: traços fundamentais de uma hermenêutica filosófica. 14. ed. Petrópolis: Vozes; Bragança Paulista: Editora Universitária, 2014.
GAGNEBIN, Jeanne M. Uma filosofia do cogito ferido: Paul Ricoeur. Estudos Avançados, São Paulo, v. 11, n. 30, p. 261-272, ago. 1997. Disponível em: $<$ http://www.scielo.br/scielo.php?script=sci arttext\&pid=S0103-40141997000200016\&lng= en\&nrm=iso > . Acesso em: 31 ago. 2017.

GILES, Thomas R. História do existencialismo e da fenomenologia. São Paulo: EPU, 1975.

INWOOD, Michael. Dicionário Heidegger. Rio de Janeiro: Jorge Zahar, 2002.

JESUINO, Jorge C. Um conceito reencontrado. In: OLIVEIRA, Angela M.; ALMEIDA, Maria F. S. Santos; TRINDADE, Zeidi A. (orgs.). Teoria das representações sociais: 50 anos. Brasília: Technopolitik, 2014. p. 41-75.

KAHLMEYER-MERTENS, Roberto S. 10 lições sobre Heidegger. Petrópolis, RJ: Vozes, 2015.

LUIJPEN, Wilhelmus A. M. Introdução à fenomenologia existencial. São Paulo: EPU, 1973.

MACEDO, Fernanda M. F.; BOAVA, Diego L. T. Fenomenologia social: possibilidades para a pesquisa organizacional. In: ENCONTRO DE ESTUDOS ORGANIZACIONAIS DA ANPAD. 7., 2012, Curitiba. Anais... Curitiba. Disponível em: <http://www.anpad.org.br/diversos/ trabalhos/EnEO/eneo_2012/2012_ENEO391. pdf > . Acesso em: 20 jan. 2016.

MARTINS, Mizael O. F. Linguagem e angústia, existência e cuidado do Dasein em Heidegger. Revista Diálogos, Paraná, n.10, p. 224-49, 2013.

MOHER; David et al. The prisma Group. Preferred reporting items for systematic reviews and meta-analyses: the prisma Statement. PLoS Medicine, San Francisco, v. 6, n. 7, 2009. Disponível em: <https://goo.gl/36MKoH>. Acesso em: 10 fev. 2015.

MOSCOVICI, Serge. Representações sociais: investigações em psicologia social. Editado em inglês por Gerard Duveen. Traduzido por Pedrinho A. Guareschi. 5. ed. Petrópolis: Vozes, 2007. 
RANIERI, Leandro P; BARREIRA, Cristiano R. A. A entrevista fenomenológica. In: SEMINÁRIO INTERNACIONAL DE PESQUISA E ESTUDOS QUALITATIVOS SIPEQ. 4., 2010, Rio Claro. Anais... Rio Claro. Disponível em: $<$ http://www.sepq.org.br/IVsipeq/anais/ artigos/46.pdf $>$. Acesso em: 2 fev. 2015.

SAFRANSKY, Rüdiger. Heidegger, um mestre na Alemanha: entre o bem e o mal. São Paulo: Geração Editorial, 2000.

SCHMIDT, Laurence K. Hermenêutica. Petrópolis: Vozes, 2012.
VAN-MANEN, Max. Phenomenology of practice: meaning-giving methods in phenomenological research and writing. Walnut Creek California: Left Coast Press, 2014.

WAGNER, Helmut R. A abordagem fenomenológica da sociologia. In: WAGNER, Helmut R. (org.). Fenomenologia e relações sociais: textos escolhidos de Alfred Schutz. Rio de Janeiro: Zahar, 1970. p. 3-50.

Recebido em 22/07/2016.

Aprovado em 21/10/2017. 